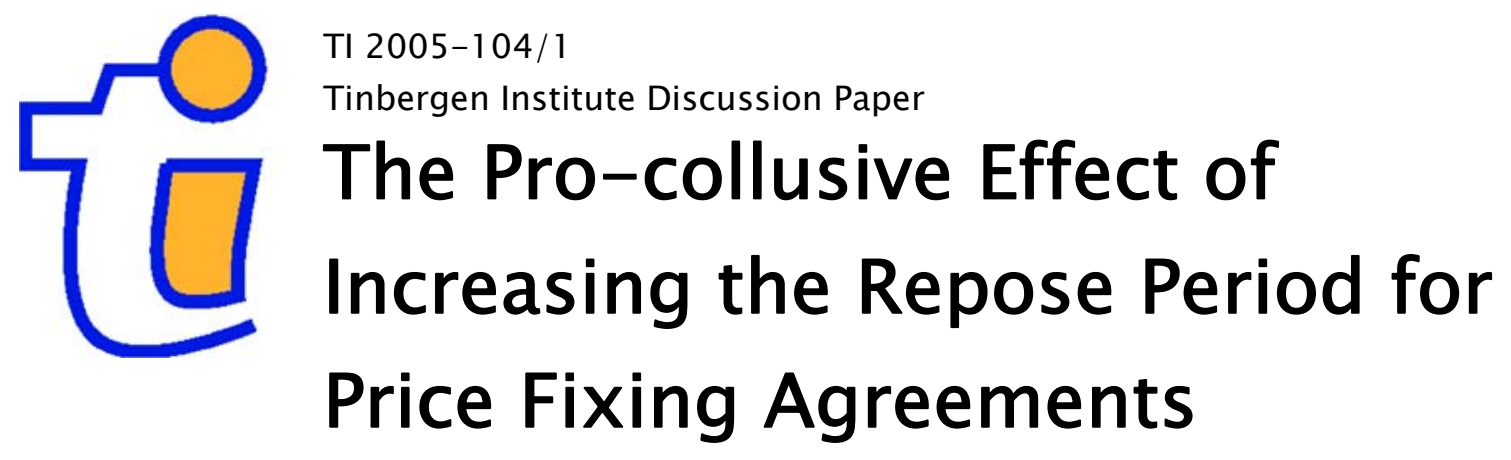

Jeroen Hinloopen

University of Amsterdam, Tinbergen Institute, and Economics Network for Competition and Regulation (ENCORE). 


\section{Tinbergen Institute}

The Tinbergen Institute is the institute for economic research of the Erasmus Universiteit Rotterdam, Universiteit van Amsterdam, and Vrije Universiteit Amsterdam.

Tinbergen Institute Amsterdam

Roetersstraat 31

1018 WB Amsterdam

The Netherlands

Tel.: $\quad+31(0) 205513500$

Fax: $\quad+31(0) 205513555$

Tinbergen Institute Rotterdam

Burg. Oudlaan 50

3062 PA Rotterdam

The Netherlands

Tel.: $\quad+31(0) 104088900$

Fax: $\quad+31(0) 104089031$

Please send questions and/or remarks of nonscientific nature to driessen@tinbergen.nl.

Most TI discussion papers can be downloaded at http://www.tinbergen.nl. 


\title{
The pro-collusive effect of increasing the repose period for price fixing agreements.
}

\author{
Jeroen Hinloopen, ${ }^{* \dagger}$ \\ University of Amsterdam (and Tinbergen Institute) \\ and \\ Economics Network for Competition and Regulation (ENCORE)
}

November 2005

\begin{abstract}
Intuitively, extending the period of repose for price fixing agreements enhances the effectiveness of competition policy enforcement. This paper proofs this intuition wrong. As extending the repose period reduces cartel members' defection payoff while it leaves unaltered expected compliance profits, it induces cartels to be more stable internally.
\end{abstract}

Key words: Cartel stability, detection probabilities, statue of limitation.

JEL Classification: K21, K42, L12, L41

\footnotetext{
${ }^{*}$ Correspondence: University of Amsterdam, School of Economics, Roetersstraat 11, 1018 WB Amsterdam, The Netherlands; e-mail: J.Hinloopen@uva.nl; http://www.fee.uva.nl/io/jhinloopen.

${ }^{\dagger}$ Thanks are due to two anontmous referees for their constructive comments.
} 


\section{Introduction}

Two years before joining the European Union in 1995, Sweden adopted its own competition law. The concomitant Swedish Competition Act contains basic prohibitions against the abuse of dominant positions and against pricefixing agreements, much in line with Articles 81 and 82 of the EU Treaty and with the US Sherman Act. Meanwhile Sweden has joined the EU and is confronted with the more decentralized implementation of EU competition articles as a result of the recent modernization of EU competition policy. In order to facilitate obtaining compensation for injured parties for instance, early 2004 a Swedish government committee made several proposals, including an extension of the repose period from five to ten years for violating the Competition Act. This means a proposed extension of the period during which parties can be prosecuted that reached at some stage a price-fixing agreement. $^{1}$

In all jurisdictions with effective competition policy enforcement, periods of repose exist for violations of competition law, including the five year period enacted in both the US and the EU. Among the reasons for such a repose period to exist are that evidence is lost over time, memories tend to fade, and a balanced assessment of the past becomes more and more difficult the further away the past is.

At an intuitive level extending this repose period appears as enhancing the effectiveness of competition policy enforcement. If competition authorities have more time to complete the proof of price-fixing agreements, the likelihood of successful cartel prosecutions should increase. And the need for improved enforcement of competition policies is widely shared; reviewing the empirical literature on cartel detection published in the period 1998 - 2004, Bush et al. (2004) in a brief amicus curiae to the Court of Appeals for the District of Columbia Circuit conclude that

... sanctions are much less than the amount needed to discourage future cartel formation. One of the best ways to discourage cartels is to increase the expected costs in the event the participants are caught, in order that the expected penalties exceed the expected benefits.

\footnotetext{
${ }^{1}$ See Mannheimer Swartling (2005). Note that there are two relevant statutes of limitation regarding the time span prosecution is still possible: the period of limitation, which refers to number of years prosecution is possible after the violation is discovered, and the period of repose, which is the number of years prosecution is possible after the violation has occurred. Throughout this paper the focus is on the period of repose.
} 
Indeed, an extended period of repose could be considered a straightforward way to increase the expected cost of entering a price-fixing agreement.

In this paper we proof this idea wrong. As the period of repose does not affect expected collusion profits, extending the repose period does not diminish the expected rewards from adhering to a price-fixing agreement. It does affect however the expected benefits from defection, but extending the repose period reduces defection payoffs as it increases the expected fine after defection. Accordingly, an extended repose period induces a cartel to be more stable internally.

To formalize this reasoning the incentive compatibility constraints (ICCs) for internal cartel stability are considered. As these constraints indicate when defection from an existing cartel is not profitable, they do not rule the decision to join a cartel as such. Hence, an extended repose period does not carry a counter-deterrent effect on cartel formation. However, as for every cartel extending the period of repose relaxes the most binding ICC, at any point in time more cartels will exist. In this sense extending the repose period does encourage cartels to be realized.

For establishing the pro-collusive effect of extending the period of repose a non-stationary supergame is considered in that per-period cartel detection probabilities are allowed to change over time. This framework encompasses the case where the detection probability changes when a cartel ceases to exist (Cyrenne, 1999, Harrington, 2004). Indeed, also for this scenario the identified pro-collusive effect stands.

The paper's policy implication is straightforward: the period of repose for violating competition policy on price-fixing agreements should be as short as possible. This resembles very much the working of corporate leniency programs. According to these programs the cartel member that is the first to report the cartel to the competition authorities is granted full immunity from further prosecution upon further cooperation with the authorities, including to turn in former cartel partners (Spagnolo, 2004). Eliminating the repose period has the same effect without however carrying the burden for the defecting firm of future retaliation by its former partners in crime. This absence might make defection more attractive. ${ }^{2}$

In what follows first the model is introduced and in Section 3 the ICCs for internal cartel stability are derived. From these the main proposition of the paper follows, and Section 4 concludes.

\footnotetext{
${ }^{2}$ Experimental research shows however that this is not the case; the probability that a cartel is formed again is not affected by the way the cartel has collapsed (i.e. defection versus leniency application, see Hinloopen and Soetevent, 2005).
} 


\section{The model}

A group of $m \geq 2$ symmetric firms starts colluding by quoting a joint price $p^{J}$ at $t=1$. Each cartel member then knows that there is a probability $p_{t} \in(0,1)$ that the cartel is discovered by the antitrust authorities in period $t$, for $t=1,2, \ldots$. This per-period cartel detection probability is allowed to vary between periods but typically is about 15\% (Bryant and Eckard, 1991). The probability that the cartel is discovered from period $t$ through period $t+k$ then equals:

$$
P_{t}(k)=1-\prod_{j=0}^{k}\left(1-p_{t+j}\right) .
$$

Note that $P_{t}(0)=p_{t}$, and that $P_{t}(k)$ is increasing in $k$, with $\lim _{k \rightarrow \infty} P_{t}(k)=$ 1 .

In case firms would not collude they would all charge the noncooperative Nash equilibrium price, $p^{N}$. The collusive price is sustained as a subgame perfect Nash equilibrium (SPNE) with Friedman's (1971) trigger strategy profile:

$$
\begin{aligned}
s_{i}^{1} & =p^{J}, \\
s_{i}^{t} & =\left\{\begin{array}{l}
p^{J} \text { if } p_{j}^{k}=p^{J}, k=1, \ldots, t-1, j=1, \ldots, m, \\
p^{N} \text { otherwise }
\end{array}\right.
\end{aligned}
$$

$t=2, \ldots, i=1, \ldots, m$.

\subsection{Collusive payoffs}

Per-firm single-period profits compare as follows: $0 \leq \pi^{N}<\pi^{J}$. Given (1) and (2) compliance profits gross of fine payments earned during period $t+k$ as expected at the beginning of period $t$ are:

$$
v_{t}^{J}(k)=\left[1-P_{t}(k)\right] \pi^{J}+P_{t}(k) \pi^{N},
$$

where $\lim _{k \rightarrow \infty} v_{t}^{J}(k)=\pi^{N}$. In addition, if the cartel is broken up because antitrust authorities have discovered it, all members have to pay a fine $F$ once. In most jurisdictions for individual firms this fine is bounded to be below some percentage of gross annual turnover (Connor, 2004). At the beginning of period $t$ every cartel member expects in period $t+k$ a fine payment of: 


$$
F_{t}(k)=\left\{\begin{array}{cc}
p_{t} F & \text { if } k=0, \\
{\left[1-P_{t}(k-1)\right] p_{t+k} F} & \text { otherwise. }
\end{array}\right.
$$

From (4) it is immediate that an increase in some per-period detection probability increases the expected fine for that period. At the same time, as $P_{t}(k)$ is increasing in any $p_{j}, t \leq j \leq t+k$, an increase in per-period detection probability in period $t$ diminishes the expected fine payment for any later period as the probability of reaching that period as a cartel is reduced. The net result of these two opposing forces rules the impact of an increase in some per-period detection probability on the overall expected fine payment. As shown by Hinloopen (2005), an increase in any per-period detection probability increases total expected fine payments.

Let future periods be discounted with rate $\delta \in(0,1)$. The expected present discounted value at the beginning of period $t$ of cartel compliance then equals:

$$
V_{t}^{J}=\sum_{i=0}^{\infty} \delta^{i}\left[v_{t}^{J}(i)-F_{t}(i)\right]
$$

\subsection{Defection and repose period}

Any cartel member can defect at any time from the non-binding agreement to quote the joint price $p^{J}$. Per-period defection profits $\pi_{i}^{\text {defect }}$ are earned with probability $\left(1-p_{t+d}\right)$ if the defector defects at the beginning of period $t+d .^{3}$ To make defection credible let $\pi^{\text {defect }}>\pi^{J}>\pi^{N}$. At the same time with probability $p_{t+d}$ the cartel is discovered and all firms, including the defecting firm, earn $\pi^{N}$ only. ${ }^{4}$ Whether or not the cartel is detected, according to (2) defection is always followed by retaliation to non-cooperative Nash behaviour. Defection profits gross of fine payments earned during period $t+d$ as expected at the beginning of period $t$ thus equal:

$$
v_{t}^{\text {defect }}(d)=\left[1-P_{t}(d)\right] \pi^{\text {defect }}+P_{t}(d) \pi^{N},
$$

where $\lim _{d \rightarrow \infty} v_{t}^{\text {defect }}(d)=\pi^{N}$.

The repose period extends $n$ periods after the defection period; as of period $t+d+n$ prosecution is not possible anymore. Note that if the cartel

\footnotetext{
${ }^{3}$ We ignore here the effect of defection on the probability of defection; see Cyrenne (1999), and Harrington (2004).

${ }^{4}$ It is for computational convenience assumed that the defecting firm earns $\pi^{\text {defect }}$ with probability $\left(1-p_{t+d}\right)$ only; the main point of the paper, stated in Proposition 2 below, would not alter if the defecting firm earns $\pi^{\text {defect }}$ with certainty.
} 
is detected in period $t+d+j \leq t+d+n$ an upperbound on the limitation period emerges, being $n-j$. Indeed, extending the repose period corresponds to increasing the upperbound on the limitation period.

The present discounted value at the beginning of period $t$ of the expected fine payment when defecting at the beginning of period $t+d$ is given by:

$$
\Gamma_{t}(d \mid n)=\sum_{i=0}^{n+d} \delta^{i} F_{t}(i)
$$

Obviously, $\Gamma_{t}(d \mid n)$ is increasing in $n$; the longer is the period of repose, the higher is the total expected fine to be paid after defection. At the same time, the total expected fine payment when colluding equals $\lim _{x \rightarrow \infty} \Gamma_{t}(x \mid n)=$ $\sum_{i=1}^{\infty} \delta^{i} F_{t}(i)$, which does not depend on the repose period.

In sum, the expected present discounted value at the beginning of period $t$ of defection during period $t+d$ equals:

$$
V_{t}^{\text {defect }}(d \mid n)=\sum_{i=0}^{d-1} \delta^{i} v_{t}^{J}(i)+\delta^{d} v_{t}^{\text {defect }}(d)+\sum_{i=d+1}^{\infty} \delta^{i} \pi^{N}-\Gamma_{t}(d \mid n)
$$

\section{$3 \quad$ Internal cartel stability and repose period}

The ICCs for internal cartel stability follow from solving $(5) \geq(8)$ and read as (see Appendix 1):

$$
\begin{aligned}
\frac{\pi^{\text {defect }}-\pi^{J}}{\pi^{J}-\pi^{N}} & \leq \sum_{i=1}^{\infty} \delta^{i} \prod_{j=1}^{i}\left(1-p_{t+d+j}\right)-\widetilde{F} \sum_{i=n+1}^{\infty} \delta^{i} p_{t+d+i} \prod_{j=1}^{i-1}\left(1-p_{t+d+j}\right) \\
& =S(t+d \mid n)
\end{aligned}
$$

$t=1,2, \ldots, d=1,2, \ldots .$, where $\widetilde{F}=F /\left(\pi^{J}-\pi^{N}\right)$. Obviously, $S(t+d \mid n)=$ $S\left(t^{\prime}+d^{\prime} \mid n\right)$ for any $t^{\prime}$ and $d^{\prime}$ such that $t^{\prime}+d^{\prime}=t+d$. Accordingly, denote the RHS of (9) by $S(k \mid n)$, with $k=t+d$.

Among the infinite number of ICCs in (9) there is one that is most binding:

Lemma 1 If $\delta \in(0,1), n \geq 1, p_{t} \in[0,1]$, and $\exists t>1 \mid p_{t} \in(0,1)$, then $\forall k>1$ (i) $S(k \mid n)>0$ and (ii) $S(k \mid n)$ is a monotone mapping from $\mathbb{N}_{+}$ onto $\mathbb{R}_{+}$.

Proof. See Appendix 2 
Lemma 1 implies that the minimum over $k$ of $S(k \mid n)$ exists and that it is unique. For future reference, let $S\left(k^{*} \mid n\right)=\min _{\{k\}} S(k \mid n), k>1$.

Having characterized the constraint that rules the non-stationary supergame the main question of the paper can addressed. That is, what is the effect of changing $n$ on the cartel's internal stability? The next proposition clarifies:

Proposition 2 An increase in $n$ reduces the domain for which the strictest ICC for internal cartel stability is binding.

$$
\text { Proof. } S\left(k^{*} \mid n+1\right)-S\left(k^{*} \mid n\right)=\widetilde{F} \delta^{n+1} p_{k^{*}+n+1} \prod_{j=1}^{n}\left(1-p_{k^{*}+j}\right)>0 \forall n>1 \text {. }
$$

According to Proposition 2 the strictest ICC for internal cartel stability becomes less binding the longer antitrust authorities continue to prosecute former cartel members after defection. Legislation that extends the period of repose for violating antitrust laws strengthens rather than weakens cartel stability. This possibly paradoxical result is due to the reduction in expected defection profits as a result of an extended period of limitation; defection becomes less profitable the longer the threat is present of prosecution and concomitant fine payment after defection. And because the repose period does not affect expected profits of collusion, extending this period makes any cartel more stable internally.

\section{Conclusions}

It is widely held that it pays for firms to engage in price fixing agreements. While these agreements are illegal and therefore come with an expected fine payment, in an expected sense the benefits outweigh these costs. Antitrust authorities typically have limited resources such that a careful design of antitrust legislation is a necessary complement for effectively banning cartel formations. This design includes the period during which former cartel members can be found guilty of having participated in an illegal price-fixing agreement in the past: the period of repose.

It is tempting to conclude that an extended repose period would make cartels less attractive. This paper proofs this conjecture to be false; extending the repose period for violating antitrust legislation, in particular the fixing of prices, induces cartels to be more stable internally. The explanation for this counter-intuitive result is that the repose period affects prospective fine payments in case of cartel defection while it does not affect expected 
fine payments in case of collusion. Accordingly, extending the repose period makes defection less attractive while it leaves the expected benefits of collusion unaffected.

The formalization of this intuition is given using a nonstationary supergame in which per-period detection probabilities can vary over time. Although this setting encompasses many special cases, including the stationary version of the supergame for which per-period detection probabilities are constant over time, there is still scope for further extensions. These include the consideration of collusive strategies that prescribe shorter-lived but more intense retaliation phases, of asymmetries among cartel members, and of the possibility for cartel members to make use of corporate leniency programs. Although these extension would all give additional insights, we conjecture that the main finding of this paper is robust to these variations.

\section{References}

[1] Bryant, P. G. and Eckard, E. W., 1991, "Price fixing: the probability of getting caught", The Review of Economics and Statistics, 73(): 531 536.

[2] Bush, D., Connor, J. M., Flynn, J. J., Ghosh, S., Grimes, W., Harrington, J. E., Jr., Hawker, N., Lande, R., Shepherd, W. G. and Semeraro, S., 2004, "How to block cartel formation and price-fixing", Brief Amicus Curiae, Court of Appeals for the District of Columbia Circuit.

[3] Connor, J. M., 2004, "Global antitrust prosecutions of modern international cartels", Journal of Industry, Competition and Trade, 4(): 239 267.

[4] Cyrenne, P., 1999, "On antitrust enforcement and the deterrence of collusive behaviour", Review of Industrial Organization, 14 (): 257 - 272.

[5] Friedman, J. W., 1971, "A non-cooperative equilibrium for supergames", Review of Economic Studies, 38,(): 1 - 12.

[6] Harrington, J. E., Jr., 2004, "Cartel pricing dynamics in the presence of an antitrust authority", RAND Journal of Economics, 35(4): 651 - 673.

[7] Hinloopen, J., 2005, "Internal cartel stability with time-dependent detection probabilities", International Journal of Industrial Organization, forthcoming. 
[8] Hinloopen, J., and Soetevent, A., 2005, "Trust and recidivism; the partial success of leniency programs in the laboratory", paper presented at the annual conference of the European Association for Research in Industrial Economics (EARIE), August 2005, Oporto.

[9] Spagnolo, G., 2004, "Divide et impera: optimal leniency programs", CEPR Working Paper, No. 4840.

\section{Appendix 1 Incentive compatibility}

$$
\begin{aligned}
V_{t}^{J} & =\sum_{i=0}^{\infty} \delta^{i}\left[\left(1-P_{t}(i)\right) \pi^{J}+P_{t}(i) \pi^{N}-F_{t}(i)\right] \\
& =\sum_{i=0}^{d-1} \delta^{i} v_{t}^{J}(i)+\sum_{i=d}^{\infty} \delta^{i}\left[\left(1-P_{t}(i)\right) \pi^{J}+P_{t}(i) \pi^{N}\right]-\sum_{i=0}^{\infty} \delta^{i} F_{t}(i) \\
& \geq \sum_{i=0}^{d-1} \delta^{i} v_{t}^{J}(i)+\delta^{d}\left(1-P_{t}(i)\right) \pi^{\text {defect }}+\delta^{d} P_{t}(d) \pi^{N}+\sum_{i=d+1}^{\infty} \delta^{i} \pi^{N}-\sum_{i=0}^{n+d} \delta^{i} F_{t}(i) \\
& =V_{t}^{\text {defect }}(d \mid n)
\end{aligned}
$$

$$
\begin{aligned}
& \delta^{d}\left(\pi^{\text {defect }}-\pi^{J}\right)\left(1-P_{t}(d)\right)-\sum_{i=d+1}^{\infty} \delta^{i}\left(1-P_{t}(i)\right)\left(\pi^{J}-\pi^{N}\right) \\
\leq & \sum_{i=0}^{n+d} \delta^{i} F_{t}(i)-\sum_{i=0}^{\infty} \delta^{i} F_{t}(i)=-\sum_{i=n+d+1}^{\infty} \delta^{i} F_{t}(i)
\end{aligned}
$$

$\Longleftrightarrow$

$$
\begin{aligned}
\frac{\pi^{\text {defect }}-\pi^{J}}{\pi^{J}-\pi^{N}} & \leq \frac{\sum_{i=d+1}^{\infty} \delta^{i}\left(1-P_{t}(i)\right)}{\delta^{d}\left(1-P_{t}(d)\right)}-\frac{\sum_{i=n+d+1}^{\infty} \delta^{i} F_{t}(i)}{\delta^{d}\left(1-P_{t}(d)\right)\left(\pi^{J}-\pi^{N}\right)} \\
& =\frac{\sum_{i=1}^{\infty} \delta^{i}\left(1-P_{t}(i+d)\right)}{1-P_{t}(d)}-\frac{\sum_{i=n+1}^{\infty} \delta^{i} F_{t}(i+d)}{\left(1-P_{t}(d)\right)\left(\pi^{J}-\pi^{N}\right)}
\end{aligned}
$$


Equation (9) then follows if it is realized that:

$$
\begin{aligned}
\frac{\sum_{i=1}^{\infty} \delta^{i}\left(1-P_{t}(i+d)\right)}{1-P_{t}(d)} & =\frac{\sum_{i=1}^{\infty} \delta^{i} \prod_{j=0}^{i+d}\left(1-p_{t+j}\right)}{\prod_{j=0}^{d}\left(1-p_{t+j}\right)} \\
& =\frac{\sum_{i=1}^{\infty} \delta^{i} \prod_{j=0}^{d}\left(1-p_{t+j}\right) \prod_{j=1}^{i}\left(1-p_{t+j+d}\right)}{\prod_{j=0}^{d}\left(1-p_{t+j}\right)}
\end{aligned}
$$

and also, for $n \geq 1$ :

$$
\begin{aligned}
F_{t}(i+d) & =\left[1-P_{t}(i+d-1)\right] p_{t+i+d} F=\prod_{j=0}^{i+d-1}\left(1-p_{t+j}\right) p_{t+i+d} F \\
& =\prod_{j=0}^{d}\left(1-p_{t+j}\right) \prod_{j=d+1}^{i+d-1}\left(1-p_{t+j}\right) p_{t+i+d} F
\end{aligned}
$$

\section{Appendix 2 Proof of Lemma 1}

(i) The statement that $S(k \mid n)>0$ implies that

$$
\widetilde{F}<\delta^{-n} \sum_{i=1}^{\infty}\left[p_{k^{*}+n+i} \prod_{j=1}^{n-1}\left(1-p_{k^{*}+i+j}\right)\right]^{-1} .
$$

which holds always as the RHS of (10) is unbounded for $\delta \in(0,1), n \geq 1$, $p_{t} \in[0,1]$, while $\exists t>1 \mid p_{t} \in(0,1)$.

(ii) First note that:

$$
\begin{aligned}
S(k \mid n)= & \delta\left(1-p_{k+1}\right)+\sum_{i=2}^{\infty} \delta^{i} \prod_{j=1}^{i}\left(1-p_{k+j}\right) \\
& -\widetilde{F} \delta^{n+1} p_{k+n+1} \prod_{j=1}^{n}\left(1-p_{k+j}\right)-\widetilde{F} \sum_{i=n+2}^{\infty} \delta^{i} p_{k+i} \prod_{j=1}^{i-1}\left(1-p_{k+j}\right) \\
= & \delta\left(1-p_{k+1}\right)+\delta\left(1-p_{k+1}\right) \sum_{i=1}^{\infty} \delta^{i} \prod_{j=1}^{i}\left(1-p_{k+j+1}\right) \\
& -\widetilde{F} \delta^{n+1} p_{k+n+1} \prod_{j=1}^{n}\left(1-p_{k+j}\right)-\widetilde{F} \delta\left(1-p_{k+1}\right) \sum_{i=n+1}^{\infty} \delta^{i} p_{k+i+1} \prod_{j=1}^{i-1}\left(1-p_{k+j+1}\right) \\
= & \delta\left(1-p_{k+1}\right)-\widetilde{F} \delta^{n+1} p_{k+n+1} \prod_{j=1}^{n}\left(1-p_{k+j}\right)+\delta\left(1-p_{k+1}\right) S(k+1 \mid n) .
\end{aligned}
$$


Repeated substitution then yields:

$$
\begin{aligned}
S(k \mid n)= & \sum_{i=1}^{l} \delta^{i} \prod_{j=1}^{i}\left(1-p_{k+j}\right)-\widetilde{F} \sum_{i=1}^{l} \delta^{n+i} p_{k+n+i} \prod_{j=1}^{n+i-1}\left(1-p_{k+j}\right) \\
& +\delta^{l} \prod_{j=1}^{l}\left(1-p_{k+j}\right) S(k+l \mid n),
\end{aligned}
$$

$l \in \mathbb{N}, k \in \mathbb{N}^{+}$.

Setting $S(k \mid n)=S(k+l \mid n)$ yields:

$$
\begin{aligned}
& \sum_{i=1}^{l} \delta^{i} \prod_{j=1}^{i}\left(1-p_{k+j}\right)-\widetilde{F} \sum_{i=1}^{l} \delta^{n+i} p_{k+n+i} \prod_{j=1}^{n+i-1}\left(1-p_{k+j}\right)+ \\
& \sum_{i=l+1}^{\infty} \delta^{i} \prod_{j=1}^{i}\left(1-p_{k+j}\right)-\widetilde{F} \sum_{i=l+1}^{\infty} \delta^{n+i} p_{k+n+i} \prod_{j=1}^{n+i-1}\left(1-p_{k+j}\right) \\
= & \sum_{i=1}^{l} \delta^{i} \prod_{j=1}^{i}\left(1-p_{k+j}\right)-\widetilde{F} \sum_{i=1}^{l} \delta^{n+i} p_{k+n+i} \prod_{j=1}^{n+i-1}\left(1-p_{k+j}\right)+\delta^{l} \prod_{j=1}^{l}\left(1-p_{k+j}\right) S(k \mid n),
\end{aligned}
$$

or:

$$
\begin{aligned}
S(k \mid n) & =\frac{\sum_{i=l+1}^{\infty} \delta^{i} \prod_{j=1}^{i}\left(1-p_{k+j}\right)}{\delta^{l} \prod_{j=1}^{l}\left(1-p_{k+j}\right)}-\frac{\widetilde{F} \sum_{i=l+1}^{\infty} \delta^{n+i} p_{k+n+i} \prod_{j=1}^{n+i-1}\left(1-p_{k+j}\right)}{\delta^{l} \prod_{j=1}^{l}\left(1-p_{k+j}\right)} \\
& =\sum_{i=1}^{\infty} \delta^{i} \frac{\prod_{j=1}^{i+l}\left(1-p_{k+j}\right)}{\prod_{j=1}^{l}\left(1-p_{k+j}\right)}-\widetilde{F} \sum_{i=1}^{\infty} \delta^{n+i} \frac{p_{k+n+i+l} \prod_{j=1}^{n+l+i-1}\left(1-p_{k+j}\right)}{\prod_{j=1}^{l}\left(1-p_{k+j}\right)} \\
& =\sum_{i=1}^{\infty} \delta^{i} \prod_{j=l+1}^{l+i}\left(1-p_{k+j}\right)-\widetilde{F} \sum_{i=1}^{\infty} \delta^{n+i} p_{k+n+i+l} \prod_{j=l+1}^{n+l+i-1}\left(1-p_{k+j}\right) .
\end{aligned}
$$

For (11) to hold it must be that $\forall l \in \mathbb{N}$ :

$$
\begin{aligned}
& \sum_{i=1}^{\infty} \delta^{i} \prod_{j=1}^{i}\left(1-p_{k+j}\right)-\widetilde{F} \sum_{i=1}^{\infty} \delta^{n+i} p_{k+n+i} \prod_{j=1}^{n+i-1}\left(1-p_{k+j}\right) \\
= & \sum_{i=1}^{\infty} \delta^{i} \prod_{j=1}^{i}\left(1-p_{k+j+l}\right)-\widetilde{F} \sum_{i=1}^{\infty} \delta^{n+i} p_{k+n+i+l} \prod_{j=1}^{n+i-1}\left(1-p_{k+j+l}\right),
\end{aligned}
$$

which is true only in case $p_{t}=p \forall t>1$, thus contradicting in general the claim that $S(k \mid n)=S(k+l \mid n)$. 